\title{
BMJ open Seasonality, incidence and prognosis in atrial fibrillation and stroke in Denmark and New Zealand
}

\author{
Anette Luther Christensen, ${ }^{1}$ Lars Hvilsted Rasmussen, ${ }^{1,2}$ Michael G Baker, ${ }^{3}$ \\ Gregory Y H Lip, ${ }^{4}$ Claus Dethlefsen, ${ }^{1}$ Torben Bjerregaard Larsen ${ }^{1,2}$
}

To cite: Christensen $\mathrm{AL}$ Rasmussen LH, Baker MG, et al. Seasonality, incidence and prognosis in atrial fibrillation and stroke in Denmark and New Zealand. 2012;2:e001210.

doi:10.1136/bmjopen-2012001210

- Prepublication history and additional material for this paper are available online. To view these files please visit the journal online (http://dx. doi.org/10.1136/bmjopen2012-001210).

Received 23 March 2012 Accepted 24 July 2012

This final article is available for use under the terms of the Creative Commons Attribution Non-Commercial 2.0 Licence; see http://bmjopen.bmj.com

1Department of Cardiology, Aalborg AF Study Group, Center for Cardiovascular Research, Aalborg Hospital, Aarhus University Hospital, Aalborg, Denmark

${ }^{2}$ Thrombosis Research Unit, Aalborg University, Aalborg, Denmark

${ }^{3}$ Department of Public Health, University of Otago, Wellington, New Zealand ${ }^{4}$ University of Birmingham Centre for Cardiovascular Sciences, City Hospital, Birmingham, UK

Correspondence to Anette Luther Christensen; anluc@rn.dk

\section{ABSTRACT}

Objectives: There are relatively few large studies of seasonal variation in the occurrence of stroke in patients with atrial fibrillation (AF). We investigated the seasonal variation in incidence rates of hospitalisation with stroke in patients from Denmark and New Zealand.

Design: Cohort study.

Setting: Nationwide hospital discharge data from Denmark and New Zealand.

Participants: 243381 (median age 75) subjects having a first-time hospitalisation with $\mathrm{AF}$ in Denmark and 51480 (median age 76) subjects in New Zealand constituted the study population. Subjects with previous hospitalisation with stroke were excluded.

Primary and secondary effect measures: Peak-totrough ratio of the seasonal variation in incidence rates of stroke in AF patients adjusted for an overall trend was primary effect measure and was assessed using a log-linear Poisson regression model. Secondary effect measures were incidence rate ratios of AF and 30-day case fatality for stroke patients.

Results: Incidence rates of AF per 1000 person-years in Denmark increased by $5.4 \%(95 \% \mathrm{Cl} 5.3 \%$ to $5.7 \%)$ for patients aged $<65$ and $5 \%(95 \% \mathrm{Cl} 4.9 \%$ to $5.1 \%)$ for patients aged $\geq 65$, whereas the increase was $0.2 \%$ $(95 \% \mathrm{Cl}-0.2 \%$ to $0.6 \%)$ for patients aged $<65$ and $2.6 \%(95 \% \mathrm{Cl} 2.4 \%$ to $2.8 \%)$ for patients aged $\geq 65$ in New Zealand. In Denmark 36088 subjects were hospitalised with stroke, and 7518 subjects in New Zealand, both showing peaks during winter with peakto-trough ratios of 1.22 and 1.27 , respectively and a decreasing trend. The 30-day case fatality risk for stroke patients having AF is now (2000-2008) about $20 \%$ in both countries.

Conclusions: Although incidence rates of hospitalisation with stroke in patients with AF have decreased in recent years, stroke remains a common AF complication with a high case fatality risk. The marked winter peak in incidence rates of hospitalisation with stroke in AF patients suggests that there are opportunities to reduce this complication. Further studies are necessary to identify how to optimise treatment of $\mathrm{AF}$ and prevention of stroke.

\section{ARTICLE SUMMARY}

Article focus

- Explore trends in incidence rates of atrial fibrillation (AF) in the entire Danish and New Zealand population.

- Estimate the peak-to-trough ratio of hospitalisations with stroke in AF patients in a cohort study design based on discharge data from Denmark and New Zealand using a log-linear Poisson regression model adjusted for an overall trend.

- Estimate 30-day case fatality risks for stroke in AF patients in Denmark and New Zealand.

Key messages

- The incidence rates of AF in entire Danish and New Zealand population have increased since start of registration of hospitalisations until 2008.

- Hospitalisations with stroke in AF patients show similar seasonal variation with a peak during winter and trough during summer in countries in opposite hemispheres.

- The 30-day case fatality risk for stroke in $\mathrm{AF}$ patients seems to have been at a constant level during 2000-2008.

Strengths and limitations

- The main strength of this study was that study cohort is based on two entire national populations.

- The main limitation of this study was inherent to its observational nature since the negative predictive value of discharge data may not be assessed.

- The cohort study design indicates associations to be explored further to identify causality trough randomised controlled studies.

\section{INTRODUCTION}

Atrial fibrillation (AF) is the most common sustained cardiac rhythm disorder, and is associated with a substantial risk of mortality and morbidity from thromboembolism and especially thromboembolic stroke. Well-established risk factors for stroke in AF patients are prior 
stroke, advanced age, hypertension, diabetes mellitus, moderate-severe systolic dysfunction and vascular disease. ${ }^{1-3}$

A seasonal variation in acute presentation with various cardiovascular disorders has been reported, with data on acute presentations with myocardial infarction, sudden death, rupture/dissection of aortic aneurysms, heart failure hospitalisations and venous thromboembolism ${ }^{4-9}$ all showing a seasonal peak during winter. Acute stroke and transient ischaemic attack show a similar pattern. ${ }^{10} 11$

In addition, a seasonal variation in paroxysmal $\mathrm{AF}$ has been documented by 24-h Holter electrocardiogram, with maximum and minimum incidences in autumn and summer, respectively. ${ }^{12}$ It has been suggested that AF hospital admissions may also exhibit a seasonal variation, with the risk being modestly higher during the winter and inversely associated with outdoor temperature. ${ }^{13}$ Nonetheless, this effect may be small and has been considered unlikely to be significant for policy or aetiological research purposes. ${ }^{14}$ However, this may reflect the limitations of relatively small single-centre studies, and large 'real world' population-based analyses may be needed. Indeed, using the linked Scottish Morbidity Record scheme between 1990 and 1996, there was a total of 33582 male and 34463 female AF hospitalisations, which showed a substantial seasonal variation in $\mathrm{AF}$ hospitalisations and deaths, particularly in the elderly. ${ }^{15}$

Few studies exist on seasonal variation in occurrences of stroke and death risk after stroke in patients with AF. One analysis from the Danish National Registry of Patients has previously found a seasonal variation in stroke occurrence in patients with non-valvular $\mathrm{AF}$ but no effect of season on mortality after stroke. ${ }^{16}$ One small series of approximately 300 Greek patients with first-ever cardio embolic acute stroke due to $\mathrm{AF}$ also revealed a seasonal peak during winter and a decline of stroke occurrence during summer. ${ }^{17}$

Assuming a seasonal variation in hospital admissions with stroke in patients with $\mathrm{AF}$, we would expect to see similar temporal patterns in countries from different parts of the world. However, we are unaware of any data comparing seasonal changes over a comparable time period between two countries, irrespective of seasonality shift by being in the northern or southern hemisphere. In this study, we described the occurrence of hospitalisations with stroke in patients with AF, including estimating the seasonal variation in the two countries investigating the temporal patterns from the northern and southern hemisphere. Furthermore, we described the overall trend in incidence rates of hospitalisation admissions for both $\mathrm{AF}$ and stroke in patients with $\mathrm{AF}$ over a 20-year period. Differences in 30-day case fatality risks between countries were also assessed.

\section{MATERIAL AND METHODS}

Study period and study population

The study period in Denmark was from 1 January 1977 and in New Zealand from 1 January 1988, both to 31
December 2008. Hospitalisations with first-time nonvalvular $\mathrm{AF}$ and stroke were recorded using the International Classification of Diseases (ICD). Both principal and additional diagnoses were included for analysis. No discrimination was made between ischaemic or haemorrhagic strokes.

The Danish cohort was identified in the Danish National Registry of Patients, established in 1977, using the Danish Personal Identification number. This is a unique and national identification number which is part of the personal information stored in the Civil Registration System. The Danish study population in the present study included Danish residents who developed incident AF from 1977 to 2008. ICD codes were used to extract admissions for AF. The 8th revision (ICD-8) was used until 1994, and after 1994 the 10th revision (ICD-10) was used. AF and atrial flutter were coded separately in ICD-8 (codes 427.93 and 427.94), whereas in ICD-10, AF and atrial flutter have a single ICD code (I48). Therefore, atrial flutter cases have also been included in the present study. In Denmark, incidences of stroke were found in the Danish National Registry of Patients, using ICD-8 (433, 434 and 436) and ICD-10 (I63, I64). To reduce inclusion of prevalent cases of $\mathrm{AF}$ and stroke in $\mathrm{AF}$ patients, identified cases before 1980 were excluded from the analyses for the Danish cohort.

The cohort from New Zealand was identified from 1988 to 2008, using the National Minimum Dataset. The National Minimum Dataset, managed by the New Zealand Ministry of Health, holds information on all publicly funded hospitalisations in New Zealand. Each hospitalisation is linked with the patient's National Health Index (NHI) number, which is a unique number provided to each person using health and disability support services in New Zealand. This index is stored in the NHI database along with demographic details of the person. In the National Minimum Dataset ICD 9th revision (ICD-9) was used until June 1999, and after that ICD-10 was used. Similar to the Danish data, AF and atrial flutter were coded separately in ICD-9 (codes 427.31 and 427.32), whereas in ICD-10, AF and atrial flutter have a single ICD code (I48). In New Zealand, incidences of stroke were found in the National Minimum Dataset using ICD-9 (433, 434 and 436) and ICD-10 (I63 and I64). To reduce inclusion of prevalent cases of $\mathrm{AF}$ and stroke in $\mathrm{AF}$ patients, identified cases before 1991 were excluded from the analyses for the New Zealand cohort.

In Denmark annual population figures were obtained from Statistics Denmark, whereas in New Zealand only 5-year population figures were available from Statistics New Zealand starting from 1996. Annual estimates for the New Zealand population from 1988 to 2008 were obtained by linear interpolation and extrapolation.

Comorbidities were assessed by identifying hospitalisations with either congestive heart failure (ICD8: 427.09, 428; ICD9: 428 and ICD10: I11.09, I50), hypertension (ICD8: 400-404; ICD9: 401-405 and ICD10: I10-I13, 
I15), diabetes (ICD8: 249, 250; ICD9: 250 and ICD10: E11, E14), acute myocardial infarction (ICD8: 410; ICD9: 410 and ICD10: I21, I22), peripheral artery disease (ICD8: 440.2, 443, 444; ICD9: 440, 443, 444 and ICD10: I70.2, I73.9, I74.5) or coronary artery disease (ICD8: 412; ICD9: 414 and ICD10: I25.1). One subject may have more than one comorbidity.

\section{Statistical analysis}

We define three effect measures for analyses. First, incidence rates of AF, defined as the annual number of hospitalisations with $\mathrm{AF}$ divided by the annual population size. Second, incidence rates of stroke in AF patients defined as the weekly number of first-time hospitalisations with stroke having previous hospital admissions for $\mathrm{AF}$ divided by the weekly person-time at risk that is, for a given week the number of AF patients with no previous stroke. Third, 30-day case fatality risk, defined as the annual number of death among stroke patients having $\mathrm{AF}$ divided by the annual number of stroke patients having AF.

A log-linear Poisson regression model was fitted to incidence rates of $\mathrm{AF}$, adjusting for a linear trend and modelling an interaction between trend and country. The analysis was stratified on age groups $(<65$ and $\geq 65$ years of age). Only incidence rates from 1991 to 2008 were analysed.

A log-linear Poisson regression model was fitted to incidence rates of stroke in AF patients adjusted for a non-linear trend and a seasonal variation component. The seasonal variation component was specified as a sum of four sinusoids with frequencies $1-4 .{ }^{18}$ The overall trend was specified as a restricted cubic spline with five knots. ${ }^{19}$ As a measurement of the seasonal variation we estimated the peak-to-trough ratio, which is an incidence rate ratio.

A logit-linear logistic regression model was fitted to 30-day case fatality risks, adjusting for a linear trend and modelling an interaction between trend and country.

Assessments of statistically significant interaction between trend and countries were performed by a likelihood ratio test. Tests for overdispersion of Poisson models and goodness of fit, including tests for all models were performed.

The $\mathrm{p}$ values less than $5 \%$ were considered statistically significant. All analyses were performed in R V.2.15.120 using the package Peak2Trough. ${ }^{21}$

\section{RESULTS}

Demographic descriptions of the two cohorts are found in table 1. For the Danish cohort, we identified 243381 incident hospitalisations with AF for the 29-year period from 1980 to 2008, of which $48 \%$ were females. For the New Zealand cohort 51480 similar subjects were identified for the 18-year period from 1991 to 2008 (48\% females). The median age at the time of $\mathrm{AF}$ in the Danish cohort was 75.2 years, which was similar to the New Zealand cohort (75.8 years).

The distribution of diagnosis type differed in the two cohorts (table 1). In both cohorts more than half of AF diagnoses were given as a supplementary diagnosis to a principal diagnosis, with a higher proportion in New

Table 1 Demographic description of patients with AF in Denmark and New Zealand

\begin{tabular}{|c|c|c|c|}
\hline & Total & Women & Men \\
\hline \multicolumn{4}{|l|}{ Denmark } \\
\hline Number of AF & $243381(100 \%)$ & $116395(47.8 \%)$ & $126986(52.2 \%)$ \\
\hline Age at $A F$, years (median (IQR)) & $75.2(70.7-84.6)$ & $78.4(62.4-79.5)$ & $71.9(62.4-79.5)$ \\
\hline \multicolumn{4}{|l|}{ AF } \\
\hline 427.31 (ICD-8) & $75739(31.1 \%)$ & $37680(32.4 \%)$ & $38059(30.0 \%)$ \\
\hline 427.32 (ICD-8) & $7050(2.9 \%)$ & $2834(2.4 \%)$ & $4216(3.3 \%)$ \\
\hline 148 (ICD-10) & $160592(66.0 \%)$ & $7581(65.2 \%)$ & $84711(66.7 \%)$ \\
\hline \multicolumn{4}{|l|}{ Diagnosis type } \\
\hline Principal & $103846(42.7 \%)$ & $47585(40.9 \%)$ & $56261(44.3 \%)$ \\
\hline Additional & $139535(57.3 \%)$ & $68810(59.1 \%)$ & $70725(55.7 \%)$ \\
\hline Weekly counts (median (IQR)) & $142(99-211)$ & 69 (48-99) & $74(50-112)$ \\
\hline \multicolumn{4}{|l|}{ New Zealand } \\
\hline Number of AF & $51480(100 \%)$ & $24883(48.3 \%)$ & $26597(51.7 \%)$ \\
\hline Age at $A F$, years (median (IQR)) & $75.8(70.4-84.3)$ & $78.1(65.0-80.3)$ & $73.6(65.0-80.3)$ \\
\hline \multicolumn{4}{|l|}{ AF } \\
\hline 427.93 (ICD-9) & 17705 (34.4\%) & $8682(34.9 \%)$ & $9023(33.9 \%)$ \\
\hline 427.94 (ICD-9) & $1389(2.7 \%)$ & $515(2.1 \%)$ & $874(3.3 \%)$ \\
\hline 148 (ICD-10) & $32386(62.9 \%)$ & $15686(63.0 \%)$ & $16700(62.8 \%)$ \\
\hline \multicolumn{4}{|l|}{ Diagnosis type } \\
\hline Principal & $15501(30.1 \%)$ & $7810(31.4 \%)$ & $7692(28.9 \%)$ \\
\hline Additional & $35978(69.9 \%)$ & $17073(68.6 \%)$ & $18905(71.1 \%)$ \\
\hline Weekly counts (median (IQR)) & $53(41-63)$ & $25(19-31)$ & $27(21-33)$ \\
\hline
\end{tabular}


Zealand, than in Denmark. The median weekly count of AF hospitalisations in Denmark was 142, whereas in New Zealand the weekly count was 53 . There was no apparent sex difference in weekly counts between the cohorts.

Differences in comorbidities were apparent between Denmark and New Zealand. In table 2, characteristics of comorbidities for all AF patients are given. In general, comordibities were more present in the New Zealand cohort compared with the Danish cohort except for diabetes.

Incidence rates of AF hospitalisation in Denmark and New Zealand per 1000 person-years are shown in Figure 1. For both countries, the incidence rates for patients younger than 65 years of age were markedly lower than for patients above 65 years of age. A likelihood ratio test indicates a significant interaction between trend and country, that is, difference in increase over time in incidence rates between countries, for both age groups (both $p$ values less than 0.001). In Denmark, the incidence rates increased by $5 \%$ annually (95\% CI $4.9 \%$ to $5.1 \%$ ) for patients above 65 years of age compared with only an increase of $2.6 \%$ annually (95\% CI $2.4 \%$ to $2.8 \%$ ) for the same patients in New Zealand. For the younger patients the incidence rates increased by $5.4 \%$ annually (95\% CI $5.3 \%$ to $5.7 \%$ ) in Denmark and $0.2 \%(95 \%$ CI $-0.2 \%$ to $0.6 \%)$ in New Zealand.

During follow-up 36088 subjects were hospitalised with stroke $(55.1 \%$ females $)$ in the Danish cohort. In New Zealand the figure was 7518 (54.6\% females). The median weekly count of stroke in Denmark was 22 and 7 in New Zealand. Table 3 shows further follow-up characteristics of the two cohorts.

The seasonal variations for both the countries estimated by fitting the Poisson regression model and adjusted for an overall trend are shown in figure 2. Time for seasonal

Table 2 Comorbidities and age distribution among patients hospitalised with atrial fibrillation (AF) having at least one comorbid disorder in Denmark and New Zealand

\begin{tabular}{lll}
\hline Characteristics & Denmark & $\begin{array}{l}\text { New } \\
\text { Zealand }\end{array}$ \\
\hline $\begin{array}{l}\text { Percentage of all patients with AF } \\
\text { having at least one comorbid }\end{array}$ & 32.5 & 53.3 \\
disorder & & \\
Age, years (at time of AF) & & \\
$\quad$ Age $\geq 75$ years & 50.7 & 52.8 \\
Age 65-74 years & 26.6 & 27.1 \\
Women & 47.8 & 48.3 \\
Congestive heart failure & 9.6 & 28.4 \\
Hypertension & 11.5 & 11.9 \\
Diabetes & 6.2 & 4.4 \\
Acute myocardial infarction & 10.3 & 15.5 \\
Peripheral arterial disease & 3.5 & 5.8 \\
Coronary artery disease & 11.2 & 16.8 \\
\hline
\end{tabular}

The comorbid conditions were registered if they preceded an incident diagnosis of AF.

Data are percentages. peak in both countries was winter and time for seasonal trough was summer. The peak-to-trough ratio in Denmark was 1.22 , that is, the risk of being hospitalised with stroke in $\mathrm{AF}$ patients at peak time in winter is $22 \%$ higher compared to summer. In New Zealand the peak-to-trough ratio was 1.27 .

Incidence rates of hospitalisation with stroke in $\mathrm{AF}$ patients were overall decreasing in both countries during the study period; see figure 3 which shows the estimated trends. From 1985 to the end of study period the incidence rates in Denmark decreased markedly reaching a plateau of approximately 3.5 hospitalisations per 100 person-years during the period from the mid-1990s to 2000, followed by a further decline. Similarly, in New Zealand the incidence rates decrease markedly during the first 14 years from 1991 to 2004.

The 30-day case fatality risks for Denmark and New Zealand are shown in figure 4 . The analysis indicated that the OR for death within 30 days after stroke in $\mathrm{AF}$ patients decreased by $1.1 \%$ (95\% CI $0.83 \%$ to $1.4 \%$ ) annually in Denmark. By contrast the OR increased by $0.87 \%$ (95\% CI $-0.31 \%$ to $2.07 \%$ ) annually in New Zealand. A likelihood ratio test indicated strong evidence in favour of interaction between trend and country $(p=0.002)$. Overall, the 30 -day case fatality risk converged in both countries towards a value of about $20 \%$ during the most recent period.

All models were assessed for overdispersion and revealed no indication of such.

\section{DISCUSSION}

This study shows that stroke remains a common complication of AF. Stroke in AF patients is serious with a $20 \%$ 30-day case fatality risk in recent years (2000-2008). This study found evidence of a marked seasonal variation in incidence rates of hospitalisation with stroke in $\mathrm{AF}$ patients, with a peak in winter and a trough in summer in both countries. The analysis indicated a difference in overall trend in incidence rates of hospitalisation with stroke in AF patients between countries, Denmark tending to have lower incidence rates, compared to New

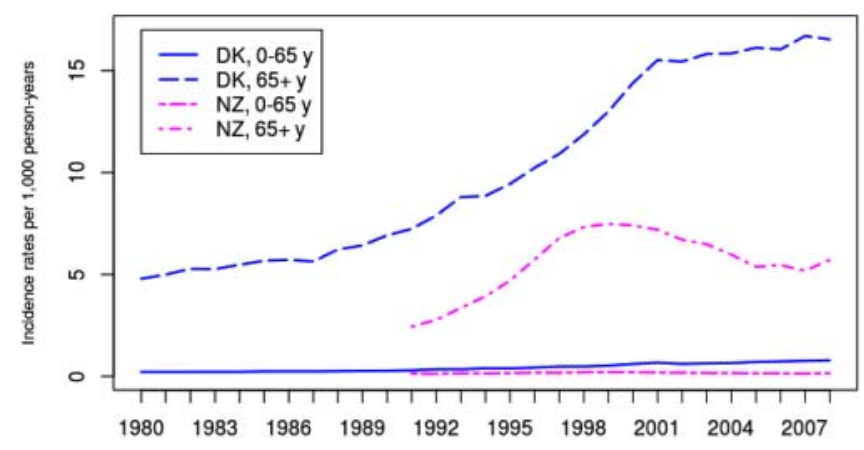

Figure 1 Observed incidence rates of first-time hospitalisation with a principal or additional diagnosis of atrial fibrillation per 1000 person-years for the Danish and New Zealand population. 
Table 3 Demographic description of patients with stroke having AF in Denmark and New Zealand

\begin{tabular}{|c|c|c|c|}
\hline & Total & Women & Men \\
\hline \multicolumn{4}{|l|}{ Denmark } \\
\hline Number of strokes & $36088(100 \%)$ & $19872(55 \%)$ & $16216(45 \%)$ \\
\hline Age at stroke, years (median (IQR)) & $79.5(76.0-86.4)$ & $81.6(69.8-82.4)$ & 76.7 (69.8-82.4) \\
\hline \multicolumn{4}{|l|}{ Stroke } \\
\hline 433 (ICD-8) & $2452(6.8 \%)$ & $1279(6.4 \%)$ & $1173(7.2 \%)$ \\
\hline 434 (ICD-8) & $1139(3.2 \%)$ & $556(2.8 \%)$ & $583(3.6 \%)$ \\
\hline 436 (ICD-8) & $8274(22.9 \%)$ & $4730(23.8 \%)$ & $3544(21.9 \%)$ \\
\hline I63 (ICD-10) & $9771(27.1 \%)$ & $5262(26.5 \%)$ & $4509(27.8 \%)$ \\
\hline 164 (ICD-10) & $14452(40.0 \%)$ & $8045(40.5 \%)$ & $6407(39.5 \%)$ \\
\hline \multicolumn{4}{|l|}{ Diagnosis type } \\
\hline Principal & $27094(75.1 \%)$ & $15110(76.0 \%)$ & $11984(73.9 \%)$ \\
\hline Additional & 8994 (24.9\%) & $4762(24.0 \%)$ & $4232(26.1 \%)$ \\
\hline Weekly counts (median (IQR)) & $22(14-31)$ & $12(8-17)$ & $10(6-14)$ \\
\hline Time to stroke, days (median (IQR)) & $380(0-1572)$ & $365(0-1528)$ & $397(0-1634)$ \\
\hline \multicolumn{4}{|l|}{ New Zealand } \\
\hline Number of strokes & $7518(100 \%)$ & $4104(54.6 \%)$ & $3414(45.4 \%)$ \\
\hline Age at stroke, years (median (IQR)) & $80.0(75.5-86.7)$ & $81.8(70.8-83.7)$ & $77.9(70.8-83.7)$ \\
\hline \multicolumn{4}{|l|}{ Stroke } \\
\hline 433 (ICD-9) & $109(1.4 \%)$ & $43(1 \%)$ & $66(1.9 \%)$ \\
\hline 434 (ICD-9) & $654(8.7 \%)$ & $337(8.2 \%)$ & $317(9.3 \%)$ \\
\hline 436 (ICD-9) & $1,288(17.1 \%)$ & $709(17.3 \%)$ & $579(17.0 \%)$ \\
\hline I63 (ICD-10) & $3581(47.6 \%)$ & $1999(48.7 \%)$ & $1582(46.3 \%)$ \\
\hline 164 (ICD-10) & $1886(25.1 \%)$ & $1016(24.8 \%)$ & $870(25.5 \%)$ \\
\hline \multicolumn{4}{|l|}{ Diagnosis type } \\
\hline Principal & $5916(78.7 \%)$ & $3227(78.6 \%)$ & $2689(78.8 \%)$ \\
\hline Additional & $1,602(21.3 \%)$ & 877 (21.4\%) & $725(21.2 \%)$ \\
\hline Weekly counts (median (IQR)) & $7(5-10)$ & $4(2-6)$ & $3(2-5)$ \\
\hline Time to stroke, days (median (IQR)) & $645(14-1776)$ & $641(17-1749)$ & $654(10-1814)$ \\
\hline
\end{tabular}

Zealand. In contrast, we showed a highly significant increase in incidence rates of AF over time in both countries. Furthermore, we found differences in the type of diagnoses in the two countries.

The main limitation of this study was inherent to its observational nature. Even though the positive predictive value of the diagnosis of $\mathrm{AF}$ is very high in the Danish registry $(93 \%),{ }^{22} 23$ the negative predictive value of such data sources is harder to assess. Consequently, studies based on hospital discharge registries may be affected by misclassification and inclusion bias-for example, by including only patients admitted to hospital with AF we might have increased the proportion of patients who were at a higher risk of thromboembolic events and death. The incidence of stroke was defined by the Danish National Registry of Patients, and not all stroke diagnoses were defined by cerebral imaging. The diagnosis of stroke has previously been validated in the Danish registry; with a positive predictive value of ischaemic stroke of $97 \% .{ }^{24}$ Also, we are limited by the inability to differentiate between ischaemic and haemorrhagic strokes, but from a Danish stroke registry we know that stroke in patients with AF is predominantly embolic. ${ }^{25}$ Stroke in AF patients by definition requires hospitalisation and recorded diagnosis for two separate conditions, so trends in incidence rates are determined by factors that affect both of these events and may be complex to interpret. Misclassification or under-reporting of comorbidities, especially hypertension and diabetes, may have occurred, ${ }^{26}$ and we did not have data on the nature of $\mathrm{AF}$ in any of the cohorts. No data exist on the validity of diagnoses on AF and stroke from the National Minimum Dataset in New Zealand. Our study included patients from Denmark and New Zealand, who were treated in different settings and probably with different methods. However, the range of patients was similar regarding age and comorbid conditions. The nature of exposures was comparable, and the definitions of outcomes were all defined by comparable ICD-coding in the two countries. The differences in healthcare systems in the two countries can hardly influence the referral pattern around AF. Furthermore, comparison of the two countries brings forward interesting questions when we compare with similar but smaller studies from other countries.

Consistent with another study we showed that the seasonal variation in incidence rates of hospitalisation with stroke in AF patients in both countries was characterised by a peak in winter and trough in summer. ${ }^{16}$ This pattern is reported for several other cardiovascular diseases. $^{4-12} \quad 15 \quad 17$ The previously reported peak-to-trough ratio from Denmark of 1.11 and pattern of seasonality ${ }^{16}$ 


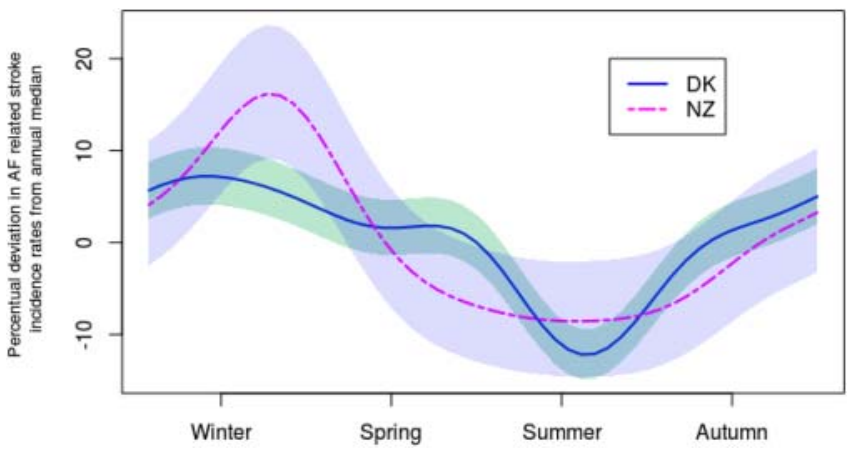

Figure 2 Estimated seasonal variation in incidence rates of hospitalisation with stroke in patients with atrial fibrillation in Denmark (solid line) and New Zealand (dashed line) adjusted for the overall trend. The seasonal variation is represented as the percentual deviation in incidence rates from annual median, and incidence rates are aggregated to weekly observations. Shaded bands represent $95 \%$ Cls.

are similar to the results reported in this study; however, the peak-to-trough ratio is slightly lower. This may be due to the difference in resolution of data. In the present study, weekly incidence rates were analysed as opposed to monthly incidence rates in Frost $e t$ al. ${ }^{16}$ The finding that the characteristics of the seasonal variation in both countries are similar may be important in the search for identifying underlying risk factors causing stroke in AF patients. Such factors may be climate factors, for example, temperature, humidity and hours of sunshine, as well as seasonal variation in occurrences of risk factors for both $\mathrm{AF}$ and stroke, for example, hypertension ${ }^{27} 28$ and infectious diseases. ${ }^{29}$ The difference in peak-to-trough ratio between two countries may also lead to the identification of causes that may explain the seasonality, by considering differences between the two countries, for instance climatic differences, housing conditions and lifestyle patterns. ${ }^{30} 31$

The overall trend in incidence rates of hospitalisation with stroke in AF patients in Denmark found in this

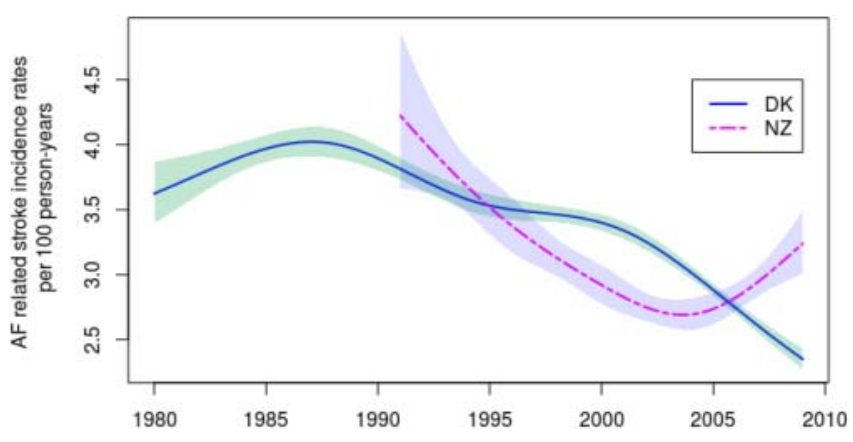

Figure 3 Estimated overall trend of Danish (solid line) and New Zealand (dashed line) weekly incidence rates of hospitalisation with stroke in atrial fibrillation patients per 100 person-years adjusted for seasonality. Shaded bands represent $95 \% \mathrm{Cls}$.

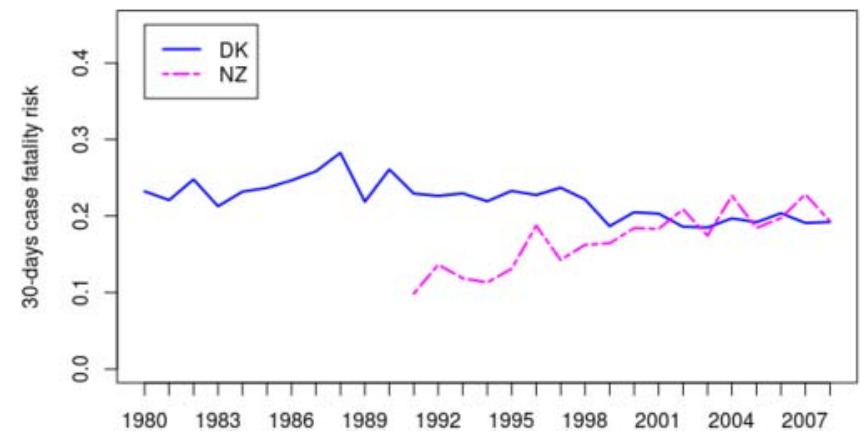

Figure 4 Observed 30-days case fatality risk for stroke in atrial fibrillation patients in Denmark and New Zealand.

study show a markedly decrease from late 1980s. During the late 1980s and early 1990s several studies regarding $\mathrm{AF}$ and its potential increasing risk of stroke were published, ${ }^{32} 33$ which led to introduction of oral anticoagulant treatment. ${ }^{34}$ 35 This concurrence reveals the prophylactic effects of anticoagulant treatment, preventing AF patients to develop stroke. However, the overall trend in incidence rates of stroke in AF patients in New Zealand indicates that the awareness of $\mathrm{AF}$ and its consequences was not as present until the early 1990s. Furthermore, this study indicates that the trend in incidence rates in Denmark is decreasing further towards the end of the study period, whereas in New Zealand the trend seems to increase.

The risk of stroke is multifactorial, and is affected by risk factors such as history of hypertension, current smoking, diet, physical activity, diabetes mellitus, alcohol intake, psychosocial stress and depression, cardiac causes (eg, AF) and ratio of apolipoproteins B to A1. ${ }^{36}$ Indeed, greater awareness of some risk factors, for example, blood pressure control and smoking cessation may have contributed to a lowering of hospitalisations with stroke in AF patients over this period. Also, a managed care approach to high-risk patients (eg, recent transient ischaemic attack) may have led to the reduction in stroke hospitalisations in recent years. ${ }^{37}$ This is clearly a positive observation, given that stroke in $\mathrm{AF}$ patients are associated with a higher mortality, as well as a greater morbidity and disability.

While the incidence rates of hospitalisation with $\mathrm{AF}$ were lower in New Zealand compared with Denmark for both age groups there was still a highly significant increase over time in incidence rates for both countries and both age groups. This is consistent with reported increasing trends in hospitalisation for AF in the USA, between 1985 and $1999 .^{38}$ In the analysis by Wattigney et al, US hospitalisations for AF increased dramatically (twofold to threefold) in the period 1985-1999. In their study, women were hospitalised with AF more often than men on an annual basis, although the age-standardised prevalence of hospitalisations was greater in men than women. Women hospitalised with AF tended to be older than men, which our results confirm. 
Unsurprisingly, we found the median age of both Danish and New Zealand cohorts to be similar (approximately 75 years). The incidence rates for patients younger than 65 years of age were much lower than for patients above 65 years of age. Indeed, these observations are consistent with other epidemiological data including analyses of hospitalisation data. ${ }^{22}$ 38-40 There was no significant sex difference in weekly counts in either cohort. Of note, the median weekly count of AF hospitalisations and stroke in AF patients in Denmark were higher than in New Zealand. The reasons for this remain uncertain, but may reflect the different demographic profile, differences in referral patterns and awareness of the disease as well as differences in associated comorbidities. Taking into account the variation in distribution of types of diagnoses of AF, where in New Zealand nearly $70 \%$ of the AF diagnoses were in addition to another principal diagnosis, compared with nearly $60 \%$ in Denmark, the difference in incidence rates of hospitalisations with $\mathrm{AF}$ may be due to differences in the health system in the two countries. In Denmark the health system is funded by taxes, and all contacts with the health system are free of charge for the patient. In contrast, in New Zealand only parts of the health system are fully funded by taxes, notably hospital care, whereas visits to the general practitioner are subject to a small user charge. Given the unspecific symptoms of AF, patients might be less likely to contact their general practitioner when experiencing symptoms with palpitations and shortness of breath. This is supported by the fact that $\mathrm{AF}$ patients with stroke often have non-recognised $\mathrm{AF}^{41}$ Consequently, a larger proportion of the New Zealand population may be undiagnosed with AF than in Denmark.

In the present study, we found some differences in comorbidities (table 2). Despite the similar age distribution between countries, especially congestive heart failure was more frequent in the New Zealand cohort and diabetes more frequent in the Danish cohort. This difference may reflect the fact that additional diagnoses for $\mathrm{AF}$ are used more frequently in the New Zealand cohort than in the Danish, and may be a random finding in patients referred with symptoms of congestive heart failure.

This study found that there was a minor decrease in the 30-day case fatality risk for stroke in AF patients during the study period in Denmark, but an increase in New Zealand. Our findings indicate that the 30-day case fatality risk in Denmark was higher than in New Zealand until the late 1990s, whereas afterwards the difference does not seem evident. This may be due to differences in anticoagulant treatments between the two countries but it also remains tentative.

\section{CONCLUSION}

This is the first concurrent analysis of the epidemiology of stroke in AF patients in nationwide population data from two western countries, one in the northern hemisphere and one in the southern hemisphere. We showed that the incidence rates of hospitalisation with stroke in AF patients exhibit a marked seasonal variation in both countries, which is characterised by a peak in winter and a trough in summer. Both countries have also shown a downward trend in hospitalisations with stroke in $\mathrm{AF}$ patients, despite a pronounced increase in AF hospitalisations. This trend, the seasonal variation and differences in comorbidities and distribution of types of diagnoses between the two countries, merit further study. Such research could help us better understand the clinical epidemiology and public health impact of $\mathrm{AF}$ and its complications and identify opportunities for better prevention of $\mathrm{AF}$ and stroke.

Contributors ALC made primary contributions to data collection and analysis, interpretation of results, and writing of the manuscript. TBL helped to write the first draft. TBL, LHR, MGB, GYHL and CD contributed to the study conception and design. All authors contributed to interpretation of results, all revised the manuscript critically for important intellectual content and all approved the final manuscript. ALC is the guarantor.

Funding The Danish Council for Strategic Research (grant no. 09-066965/ DSF).

Competing interests None.

Provenance and peer review Not commissioned; externally peer reviewed.

Data sharing statment No additional data available.

\section{REFERENCES}

1. Atrial Fibrillation Working Group. Independent predictors of stroke in patients with atrial fibrillation: a systematic review. Neurology 2007;69:546-54.

2. Hughes M, Lip GYH. Stroke and thromboembolism in atrial fibrillation: a systematic review of stroke risk factors, risk stratification schema and cost effectiveness data. Thromb Haemostasis 2008;99:295-304.

3. Rasmussen LH, Larsen TB, Due KM, et al. Impact of vascular disease in predicting stroke and death in patients with atrial fibrillation: the Danish Diet, Cancer and Health cohort study. $J$ Thromb Haemostasis 2011;9:1301-7.

4. Spencer FA, Goldberg RJ, Becker RC, et al. Seasonal distribution of acute myocardial infarction in the second National Registry of Myocardial Infarction. J Am Coll Cardiol 1998;31:1226-33.

5. Manfredini R, Manfredini F, Boari B, et al. Seasonal and weekly patterns of hospital admissions for nonfatal and fatal myocardial infarction. Am J Emerg Med 2009;27:1097-103.

6. Arntz HR, Willich SN, Schreiber C, et al. Diurnal, weekly and seasonal variation of sudden death. Population-based analysis of 24061 consecutive cases. Eur Heart J 2000;21:315-20.

7. Mehta $\mathrm{RH}$, Manfredini R, Hassan F, et al. Chronobiological patterns of acute aortic dissection. Circulation 2002;106:1110-15.

8. Gallerani M, Boari B, Smolensky $\mathrm{MH}$, et al. Seasonal variation in occurrence of pulmonary embolism: analysis of the database of the Emilia-Romagna region, Italy. Chronobiol Int J Biol Med Rhythm Res 2007;24:143-60.

9. Gallerani M, Boari B, Manfredini F, et al. Seasonal variation in heart failure hospitalization. Clin Cardiol 2011;34:389-94.

10. Manfredini R, Gallerani M, Portaluppi F, et al. Chronobiological patterns of onset of acute verebrovascular iseases. Thromb Res 1997:88:451-63.

11. Manfredini R, Manfredini F, Boari B, et al. Temporal patterns of hospital admissions for transient ischemic attack: a retrospective population-based study in the Emilia-Romagna region of Italy. Clin Appl Thromb Hemost 2010;16:153-60.

12. Watanabe $E$, Kuno $Y$, Takasuga $H$, et al. Seasonal variation in paroxysmal atrial fibrillation documented by 24-hour Holter electrocardiogram. Heart Rhythm 2007;4:27-31.

13. Frost $\mathrm{L}$, Johnsen SP, Pedersen $\mathrm{L}$, et al. Seasonal variation in hospital discharge diagnosis of atrial fibrillation: a population-based study. Epidemiology 2002;13:211-15. 
14. Upshur REG, Moineddin R, Crighton EJ, et al. Is there a clinically significant seasonal component to hospital admissions for atrial fibrillation? BMC Health Serv Res 2004;4:5.

15. Murphy NF, Stewart S, Maclntyre K, et al. Seasonal variation in morbidity and mortality related to atrial fibrillation. Int $J$ Cardiol 2004:97:283-8.

16. Frost L, Vukelic Andersen L, Mortensen LS, et al. Seasonal variation in stroke and stroke-associated mortality in patients with a hospital diagnosis of nonvalvular atrial fibrillation or flutter. A population-based study in Denmark. Neuroepidemiology 2006;26:220-5.

17. Spengos K, Vemmos K, Tsivgoulis G, et al. Diurnal and seasonal variation of stroke incidence in patients with cardioembolic stroke due to atrial fibrillation. Neuroepidemiology 2003;22:204-10.

18. Fischer T, Lundbye-Christensen S, Johnsen SP, et al. Secular trends and seasonality in first-time hospitalization for acute myocardial infarction-a Danish population-based study. Int $J$ Cardiol 2004;97:425-31.

19. Harrell FE. Regression modelling strategies-with applications to linear models, logistic regression and survival analysis. 1st edn. Springer,2001.

20. R Development Core Team. R: a language and environment for statistical computing. 2010.

21. Christensen AL. Peak2Trough: estimation of the peak-to-trough ratio of a seasonal variation component. R-package version 1.2. 2012.

22. Frost L, Andersen LV, Vestergaard $P$, et al. Trend in mortality after stroke with atrial fibrillation. Am J Med 2007;120:47-53.

23. Rix TA, Riahi S, Overvad K, et al. Validity of the diagnoses atria fibrillation and atrial flutter in a Danish patient registry. Scand Cardiovasc J 2012;46:149-53.

24. Krarup L-H, Boysen $\mathrm{G}$, Janjua $\mathrm{H}$, et al. Validity of stroke diagnoses in a National Register of Patients. Neuroepidemiology 2007;28:150-4.

25. Jørgensen HS, Plesner A-M, Hübbe $P$, et al. Marked increase of stroke incidence in men between 1972 and 1990 in Frederiksberg, Denmark. Stroke 1992;23:1701-4.

26. Chen F, Florkowski CM, Dever M, et al. Death certification and New Zealand Health Information Service (NZHIS) statistics for diabetes mellitus: an under-recognised health problem. Diabetes Res Clin Pract 2004;63:113-18.

27. Brennan PJ, Greenberg G, Miall WE, et al. Seasonal variation in arterial blood pressure. Br Med J 1982;285:919-23.
28. Kochar MS, Ristow S, Kalbfleisch JH. Effect of seasonal temperature change on blood pressure in a treated hypertensive population. J Clin Hypertens 1985;1:49-52.

29. Fisman DN. Seasonality of infectious diseases. Annu Rev Public Health 2007;28:127-43.

30. Howden-Chapman P, Crane J, Chapman R, et al. Improving health and energy efficiency through community-based housing interventions. Int J Public Health 2011;56:583-8.

31. Hales S, Blakely $\mathrm{T}$, Foster $\mathrm{RH}$, et al. Seasonal patterns of mortality in relation to social factors. $J$ Epidemiol Community 2012;66:379-84.

32. Petersen $\mathrm{P}$, Godtfredsen J. Embolic complications in paroxysmal atrial fibrillation. Stroke 1986;17:622-6.

33. Atrial Fibrillation Investigators. Risk factors for stroke and efficacy of antithrombotic therapy in atrial fibrillation. Analysis of pooled data from five randomized controlled trials. Arch Intern Med 1994;154:1449-57.

34. Stroke Prevention. Warfarin versus aspirin for prevention of thromboembolism in atrial fibrillation: stroke prevention in Atria Fibrillation II Study. Lancet 1994;343:687-91.

35. Frost L, Engholm G, Møller H, et al. Decrease in mortality in patients with a hospital diagnosis of atrial fibrillation in Denmark during the period 1980-1993. Eur Heart J 1999;20:1592-9.

36. O'Donnell MJ, Xavier D, Liu L, et al. Risk factors for ischaemic and intracerebral haemorrhagic stroke in 22 countries (the INTERSTROKE study): a case-control study. Lancet 2010;376:112-23.

37. Rothwell PM, Algra A, Amarenco P. Medical treatment in acute and long-term secondary prevention after transient ischaemic attack and ischaemic stroke. Lancet 2011;377:1681-92.

38. Wattigney WA, Mensah GA, Croft JB. Increasing trends in hospitalization for atrial fibrillation in the United States, 1985 through 1999: implications for primary prevention. Circulation 2003;108:711-16

39. Stewart S, Maclntyre K, MacLeod MM, et al. Trends in hospital activity, morbidity and case fatality related to atrial fibrillation in Scotland, 1986-1996. Eur Heart J 2001;22:693-701.

40. Humphries KH, Jackevicius C, Gong Y, et al. Population rates of hospitalization for atrial fibrillation/flutter in Canada. Can J Cardiol 2004;20:869-76.

41. Lip GYH. Stroke in atrial fibrillation: epidemiology and thromboprophylaxis. J Thromb Haemostasis 2011;9:344-51. 